\title{
Chaotropic Substances and their Effects on the Mechanical Strength of Portland Cement-Based Materials
}

\author{
Hebert Luis Rossetto ${ }^{\mathrm{a}, \mathrm{b} *}$, Milton Ferreira de Souza ${ }^{\mathrm{b}}$, Victor Carlos Pandolfelli ${ }^{\mathrm{a}}$ \\ ${ }^{a}$ Materials Engineering Department, Federal University of São Carlos, \\ Rod. Washington Luiz, Km 235, 13565-905 São Carlos - SP, Brazil \\ ${ }^{\mathrm{b}}$ Physics Institute of São Carlos, University of São Paulo at São Carlos, \\ Av. Trabalhador São-Carlense, 400, 13566-590 São Carlos - SP, Brazil
}

Received: January 24, 2008; Revised: May 10, 2008

\begin{abstract}
Portland cement-based materials are present in our everyday life. Over the last two decades, important developments have been made to improve their mechanical strength, mainly through microstructural design. In addition, another promising parameter still remains in the early stages of understanding: that of adhesion. Recently, interdisciplinary researchers have considered the issue of water confinement by the hydrated cementitious surfaces. It could contribute to increase the adhesion and strength in these materials. On the other hand, ionic and nonionic chaotropic substances might be able to disorder the structure of such special water. The results presented in this paper show important effects of these chaotropic substances on the strength of cementitious materials. They highlight the role of the confined water on the adhesion, when the microstructural parameters are kept constant. More than contributing to the fundamental understanding of adhesion within cement paste, these results provide basic insights on in-situ nanotechnology.
\end{abstract}

Keywords: adhesion, microstructure, mechanical properties, Portland cement

\section{Introduction}

Portland cement is the most important commodity for mankind, being widely used in every-day construction. Besides this importance, Double $^{1}$, over two decades ago, highlighted that the familiarity could inhibit further developments of this material. At that time, a group of researchers reported significant improvements on the mechanical strength of cementitious materials ${ }^{2}$, by manipulating microstructural parameters such as pore size. They showed that the intrinsic mechanical weakness of cementitious materials was misleading. It triggered the development of new cement products ${ }^{3}$. Double also suggested that researchers must also pay attention to promote greater cohesion within the cement paste in order to have additional breakthroughs in this area. This can be understood from the equation recently presented by Kendall ${ }^{4}$, which shows that work of adhesion (W) is vital to increase the tensile strength $(\sigma)$ as follows:

$$
\sigma=\frac{15.6 \phi^{4} \mathrm{~W}}{\sqrt{\mathrm{Dc}}}
$$

where, packing fraction $(\phi)$, particle diameter (D), and crack length (c) represent the microstructural parameters.

Nevertheless, a more feasible way to verify the adhesion effect would be by Griffith's equation. Considering that $\mathrm{W}$ is related to $\mathrm{K}_{\mathrm{IC}}$ and that in the lower part of both equations the critical crack length (c) is dominant, the adhesion changes ( $\mathrm{W}$ or $\mathrm{K}_{\mathrm{IC}}$ ) could be, at first, evaluated by the tensile strength $(\sigma)$ values. This would avoid the direct measurement of the different variables in Equation 1 or the $\mathrm{K}_{\mathrm{IC}}$ (Equation 2) in a low toughness and notch sensitive material, such as cement.

$$
\sigma=\frac{1}{\mathrm{Y}} \frac{\mathrm{K}_{\mathrm{c}}}{\sqrt{\pi \mathrm{c}}}
$$

Even though, only a few papers have dealt with adhesion. Pellenq et al. ${ }^{5}$ related it to the interaction of the hydrated cementitious phases with the adsorbed water ${ }^{6}$. In addition, it has been shown that the structure of water in the vicinity of most hydrophilic surfaces, in a distance range of 1.0-1.5 nm from a surface (the so-called "confined water"), is quite similar to that of supercooled water at a lower temperature ${ }^{7}$. The hydrophilic surfaces tend to structure the water molecules for a particular distance. As a hydrated material, it is reasonable to suppose that cement paste presents structured confined water among the particle surfaces. It has in fact been simulated by computer ${ }^{8}$ and seen by inelastic neutron scattering ${ }^{9}$. Hence, the substances which affect the confined water structure might be expected to influence the mechanical strength of Portland cement-based materials. For this reason the use of ionic and non-ionic solutions and their correlation with adhesion forces in cementitious materials is an interesting area of research to further change the mechanical strength of these materials.

\section{Experimental Procedure}

\subsection{Preparation of Portland cement plates}

Brazilian Type V cement (Holcim: $64.50 \mathrm{wt}(\%) \mathrm{C}_{3} \mathrm{~S} ; 3.78 \mathrm{wt}(\%)$ $\mathrm{C}_{2} \mathrm{~S} ; 11.50 \mathrm{wt}(\%) \mathrm{C}_{3} \mathrm{~A} ; 7.05 \mathrm{wt}(\%) \mathrm{C}_{4} \mathrm{AF} ; 7.68 \mathrm{wt}(\%)$ gypsum, where, $\mathrm{C}=\mathrm{CaO}, \mathrm{S}=\mathrm{SiO}_{2}, \mathrm{~A}=\mathrm{Al}_{2} \mathrm{O}_{3}, \mathrm{~F}=\mathrm{Fe}_{2} \mathrm{O}_{3}$ and $\mathrm{H}=\mathrm{H}_{2} \mathrm{O}$ ) was used to produce rectangular plates at a compaction pressure of $20 \mathrm{MPa}$. This processing suitably controls the microstructural reproducibility when a water-to-cement ratio (w/c) close to 0.15 is used. After being withdrawn from the die, the plates $\left(20 \times 70 \times 15 \mathrm{~mm}^{3}\right)$ had sufficient strength to support their own weight. They were cured in a humid chamber for 24 hours. At this time, the Portland cement plates achieved nearly $2 / 3$ of their highest strength attained in this work, the latter being reached after curing for 7 days by immersion in room temperature water (reference samples). 
Other samples were cured in solutions of either ionic or non-ionic substances (all of them were laboratory graded). The following ionic solutions were prepared and used: calcium hydroxide $\left(\mathrm{Ca}(\mathrm{OH})_{2}\right.$ : 30 mmol. $\mathrm{L}^{-1}$ and $1 \mathrm{~mol} . \mathrm{L}^{-1}$ ), lithium hydroxide (LiOH: $30 \mathrm{mmol} . \mathrm{L}^{-1}$ and 1 mol. $\left.\mathrm{L}^{-1}\right)$, sodium hydroxide (NaOH: 1 mol.L $\left.\mathrm{L}^{-1}\right)$, ammonium hydroxide $\left(\mathrm{NH}_{4} \mathrm{OH}: 1 \mathrm{~mol} . \mathrm{L}^{-1}\right)$, and lithium citrate $\left(30 \mathrm{mmol} . \mathrm{L}^{-1}\right)$. For non-ionic solutions, acetone (DMK: 1 mol. $\mathrm{L}^{-1}$ ), dimethylacetamide (DMA: 1 mol.L $\mathrm{L}^{-1}$ ), and dimethylformamide (DMF: $30 \mathrm{mmol} . \mathrm{L}^{-1}$ ), were prepared and tested.

\subsection{Characterization}

After curing, all samples were oven dried at $30{ }^{\circ} \mathrm{C}$ for 24 hours and, then, their mechanical strength was measured in 3-point bending ( $\operatorname{span}=45 \mathrm{~mm}$ ) using MTS (model 810) universal testing equipment. Each set of samples contained, at least, five cementitious plates. The fracture surface of the samples were characterized by scanning electron microscopy (SEM, Zeiss DSM960) in order to evaluate the microstructural changes after curing within the aforementioned solutions. Nuclear magnetic resonance $\left({ }^{29} \mathrm{Si}\right.$ MAS-NMR) was used to evaluate differences at the hydration degree of the cementitious samples. Finally, all the ionic solutions had their $\mathrm{pH}$ measured and, for non-ionic solutions, their surface tensions were evaluated by the De Nouy ring test.

\section{Results and Discussion}

All samples had the same apparent density $(\rho=2.24 \pm$ $\left.0.02 \mathrm{~cm}^{3} \cdot \mathrm{g}^{-1}\right)$, regardless the curing procedures. This aspect, associated to the same microstructural features (Figure 1), indicated that it is very likely that only the adhesion forces were influenced by the curing solutions. This is further supported by ${ }^{29} \mathrm{Si}$ MAS-NMR analysis which showed only small variations in the hydration degrees of all the samples $(42 \pm 3 \%)$, including the reference ones.

Figure $2 \mathrm{a}$ presents the bending strengths of the Portland cement plates after curing in the presence of the ionic solutions. All had a decrease in the strength compared to the reference sample $(23 \pm 3 \mathrm{MPa})$. It is noteworthy that the strength decrease was not directly related to the $\mathrm{pH}$ of the solution, but mainly to the particular ion in the solutions.

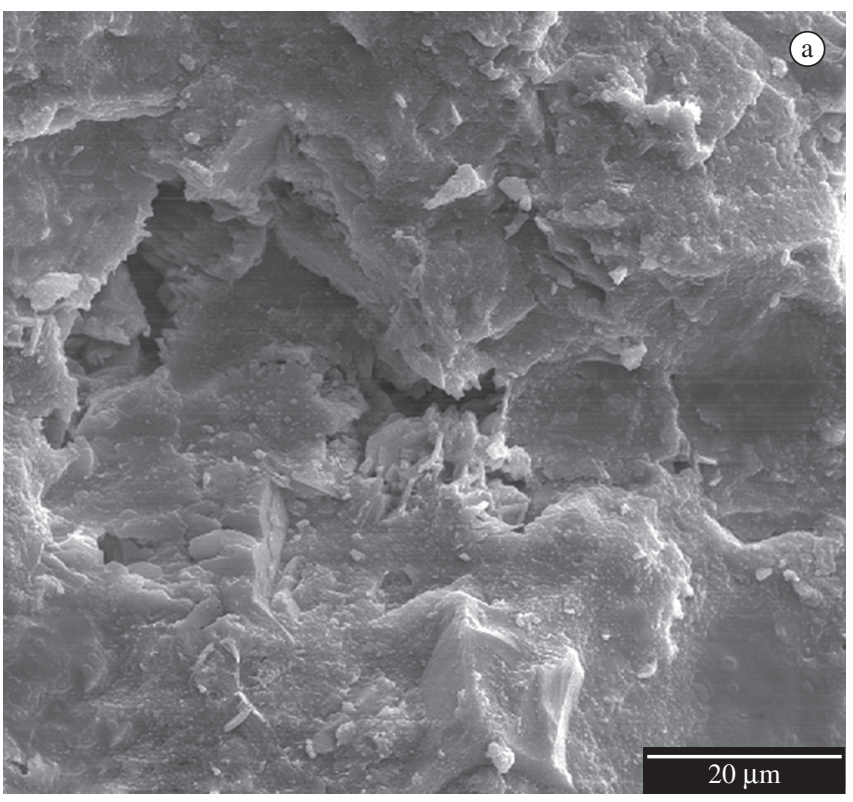

The ions follow the Hofmeister series (Figure 2b), which were originally used to classify them according to their power of precipitating or solubilizing proteins ${ }^{11}$. Lately, it has been observed that these series also reflect the ions influence on the surrounding water molecules, ranging from stabilization (kosmotropes) to disruption (chaotropes). Still, there is controversy in the scientific community about the mechanism whereby an ion can disturb the water structure ${ }^{12}$, although it is generally accepted that salts have a disordering effect on the H-bonding ${ }^{13}$ network. By comparing the results of Figure 2a to the Hofmeister series (Figure 2b), some general guidelines are evident.

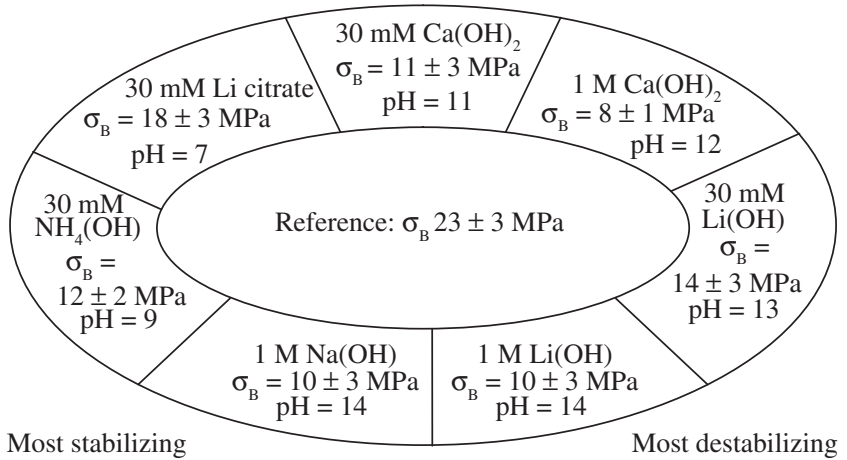

(a)

citrate $^{3--}>$ sulfate $^{2-}>$ phosphate ${ }^{2-}>\mathrm{OH}^{-}>\mathrm{F}^{-}>\mathrm{Cl}^{-}>\mathrm{Br}^{-}>\mathrm{I}^{-}>\mathrm{NO}_{3}^{-}>\mathrm{ClO}_{4}^{-}$ $\mathrm{N}\left(\mathrm{CH}_{3}\right)_{4}^{+}>\mathrm{NH}_{4}^{+}>\mathrm{Cs}^{+}>\mathrm{Rb}^{+}>\mathrm{K}^{+}>\mathrm{Na}^{+}>\mathrm{Li}^{+}>\mathrm{H}^{+}>\mathrm{Ca}^{2+}>\mathrm{Mg}^{2+}>\mathrm{Al}^{3+}$

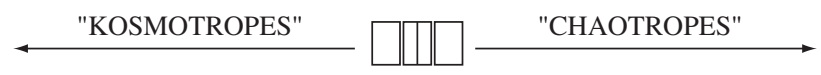

(b)

Figure 2. a) Results for 3-point bending strength of cementitious plates cured in different ionic solutions compared to the reference sample $(23 \pm 3 \mathrm{MPa})$; and b) Hofmeister series ${ }^{10}$.

Figure 1. SEM micrographs: a) reference sample; and b) sample cured with $\mathrm{Ca}(\mathrm{OH})_{2}$ aqueous solution (30 mmol/L).

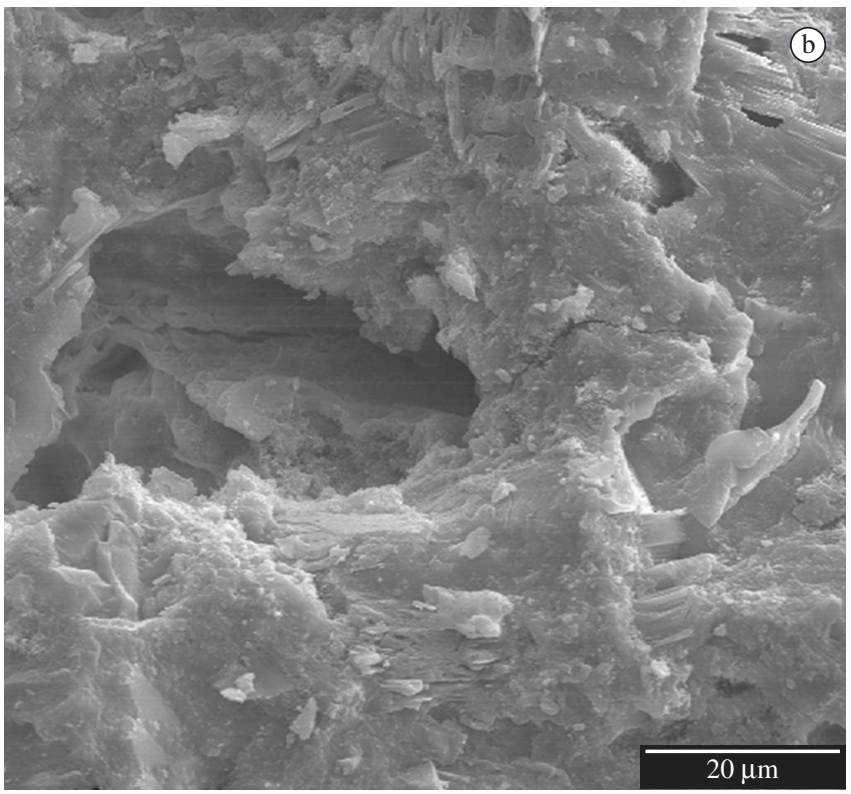


Firstly, the chaotropic cations (such as $\mathrm{Ca}^{2+}, \mathrm{Li}^{+}$, and $\mathrm{Na}^{+}$) effect on the bending strength of cementitious plates followed the destabilizing sequence of $\mathrm{Ca}^{2+}>\mathrm{Li}^{+} \approx \mathrm{Na}^{+}$. Secondly, the lower the ion concentration, the less is the bending strength decrease. These chaotropic cations were all evaluated with the same chaotropic anion: the hydroxyl $\left(\mathrm{OH}^{-}\right)$. Thirdly, this latter chaotropic anion prevailed over the kosmotropic ammonium cation effect. As expected, the anions more effectively influence the $\mathrm{H} \cdots \mathrm{OH}$ bonds ${ }^{10}$. Thus, when a strong kosmotropic anion was used in the curing solution, such as for citrate, less severe reduction was imparted to the mechanical strength.

Nevertheless, the chaotropic behavior, related to the ability to break the hydrogen bonding network of structured water, is not restricted to the ionic solutions. Non-ionic substances, such as those studied in this paper (Figure 3), have the same behavior. These include dimethylformamide (DMF), dimethylacetamide (DMA), and acetone (DMK). They have a carbonyl group $(\mathrm{C}=\mathrm{O})$ whose chaotropic tendency arises from its competition for $\mathrm{H}$-bonding with the $\mathrm{H}_{2} \mathrm{O}$ molecules. In other words, $\mathrm{C}=\mathrm{O} \cdots \mathrm{HOH}$ is more likely to be formed than $\mathrm{HOH} \cdots \mathrm{HOH}$. The aqueous solutions of these chaotropic nonionic substances also decreased the bending strength of the Portland cement-based plates, as shown in Table 1 . This is further evidence of adhesion through water confined among cementitious surfaces. Nevertheless, two other possible adhesion forces could also be actuating: the attractive van der Waals forces and the capillary ones.

Van der Waals attractive forces are inversely proportional to the medium dielectric constant $(\mathrm{k})$ : the lower the constant, the higher the forces ${ }^{14}$. Table 1 shows that all the non-ionic chaotropic solutions used in this work have a dielectric constant lower than that of deionized water; conversely, the mechanical strength of the cementitious plates decreased. This further strengthens the evidence that adhesion was determined by the confined water. Additionally, capillary forces depend on the surface tension of the liquid $(\gamma)$ : the lower this parameter, the lower the force ${ }^{15}$. The DMF in Table 1 had minor effects on the water surface tension, yet a large influence on the mechanical strength. The others, DMA and DMK, yielded a discrete drop of<smiles>CC(C)=O</smiles>

DMK

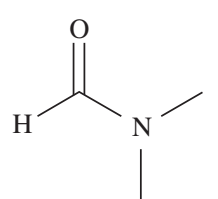

DMF<smiles>CC(=O)N(C)C</smiles>

DMA
Figure 3. Non-ionic chaotropic substances: acetone (DMK), dimethylformamide (DMF), and dimethylacetamide (DMA).

Table 1. 3-point bending strength $\left(\sigma_{\mathrm{B}}\right)$ of cement plates cured in non-ionic solutions, the dielectric constant $(\mathrm{k})$ for curing substances and the ratio between surface tension of each solution to that of deionized water $\left(\gamma_{\mathrm{SOL}} / \gamma_{\mathrm{WAT}}\right)$.

\begin{tabular}{lccc}
\hline \multicolumn{1}{c}{ Sample } & $\begin{array}{c}\sigma_{\mathrm{B}} \\
(\mathrm{MPa})\end{array}$ & $\mathrm{k}$ & $\begin{array}{l}\gamma_{\mathrm{SOL}} / \\
\gamma_{\mathrm{WAT}}\end{array}$ \\
\hline $\begin{array}{l}\text { Reference } \\
\text { (cured by immersion in water) }\end{array}$ & $23 \pm 3$ & 80 & 1.00 \\
$\begin{array}{l}\text { Cured by immersion in DMF* solution } \\
\left(30 \mathrm{mmol}^{-1}\right)\end{array}$ & $12 \pm 4$ & 37 & 0.98 \\
$\begin{array}{l}\text { Cured by immersion in DMA* solution } \\
\left(1 \mathrm{~mol}^{-1}\right)\end{array}$ & $10 \pm 3$ & 38 & 0.87 \\
$\begin{array}{l}\text { Cured by immersion in DMK* solution } \\
\left(1 \mathrm{mol.L^{-1 }}\right)\end{array}$ & $9 \pm 2$ & 21 & 0.75 \\
\hline
\end{tabular}

*DMF = dimethylformamide; DMA = dimethylacetamide; and DMK = acetone. the water surface tension that cannot be correlated with their effect on the bending strength of Portland cementitious plates. It indicates that their water structure-breaking ability prevails over their capillary force contributions.

\section{Conclusions}

Understanding the bonding of the hydrated phases of Portland cement is the first step to explore the adhesion in future developments capable of providing new cement materials or, perhaps, new applications for this old one. Although there is a lack of understanding regarding the behavior of ions or molecules to explain how they compete with water molecules near to the hydrated surfaces, this paper has shown the effects of some chaotropic substances (i.e. water-structure breaker) and how they directly influenced the bending strength of cement plates.

\section{Acknowledgements}

Our special thanks to Dr. Eduardo Azevedo (IFSC-USP) by the NMR analysis and to FAPESP and CNPq for supporting the corresponding author with academic research (02/10492-3 and 151329/2007-9). The authors also acknowledge Prof. R. Bradt for his comments to this paper.

\section{References}

1. Double DD. Cement - a respectable material? Nature 1981; 289(5796):348-349.

2. Birchall JD, Howard AJ, Kendall K. Flexural strength and porosity of cements. Nature 1981; 289(5796):388-389.

3. Richard P, Cheyrezy M. Composition of reactive powder concretes. Cement and Concrete Research 1995; 25(7):1501-1511.

4. Kendall K. Molecular adhesion and its applications: the sticky universe. New York: Kluwer Academic/Plenum Publishers; 2001.

5. Pellenq RJ, Van Damme H. Why does concrete set? Materials Research Society Bulletin 2004; 29(5):319-323.

6. Jarvis SP. Adhesion on nanoscale. In: Rosoff M, editor. Nano-surface chemistry. New York: Marcel Dekker Inc; 2002. p. 7-58.

7. Teixeira J, Zanotti JM, Bellissent-Funel MC, Chen SH. Water in confined geometries. Physica B 1997; 234-236:370-374.

8. Kalinichev AG, Wang J, Kirkpatrick RJ. Molecular dynamics modeling of the structure, dynamics and energetics of mineral-water interfaces: applications to cement materials. Cement and Concrete Research 2007; 37(3):337-347.

9. Padureanu I, Aranghel D, Rotarescu G, Dragolici F, Turcanu C, Kozlov ZA, Semenov VA. An inelastic neutron scattering study of the water dynamics in cement paste. Romanian Journal of Physics 2005; 50(5-6):561-574.

10. Chaplin M. Water structure and behavior[Online]. Avaliable from: <www.lsbu.ac.uk/water/hofmeist.html>.

11. Parsegian VA. Hopes for Hofmeister. Nature 1995; 378(6555):335-336.

12. Omta AW, Kropman MF, Woutersen S, Bakker HJ. Negligible effect of ions on the hydrogen-bond structure in liquid water. Science 2003; 301(5631):347-349.

13. Hribar B, Southall NT, Vlachy V, Dill KA. How ions affect the structure of water. Journal of American Chemical Society 2002; 124(41):12302-12311.

14. Raghavan SR, Walls HJ, Khan SA. Rheology of silica dispersions in organic liquids: new evidence for solvation forces dictated by hydrogen bonding. Langmuir 2000; 16(21):7920-7930.

15. Israelachivili J. Intermolecular and surface forces. $2^{\text {nd }}$ ed. London: Academic Press; 1992. 